\title{
Optimasi Simulasi Routing OSPF (Open Shortest Path First) di Bandara Soekarno Hatta
}

\section{Lady Silk M}

\author{
Politeknik Penerbangan Surabaya \\ Jl. Jemur Andayani I/73, Surabaya 60236 \\ Email : lady.silk@poltekbangsby.ac.id
}

\begin{abstract}
ABSTRAK
Bandar Udara Internasional Soekarno-Hatta adalah bandara terbesar di Indonesia dengan luas mencapai $18 \mathrm{~km}^{2}$, dengan rute penerbangan mencapai 1657 penerbangan setiap hari, yang merupakan penerbangan terbanyak se-Indonesia. PT. Angkasa Pura II merupakan Badan Usaha Milik Negara yang mengelola pelayanan jasa kebandar-udaraan di Bandara Soekarno Hatta. Bandara ini memiliki 3 Terminal Penumpang yaitu T1, T2, dan T3. Masing-masing terminal tersebut mempunyai beberapa sub terminal. Oleh karena begitu luas area pengelolaan dan begitu padat aktifitas penerbangan di Bandara Soekarno-Hatta, maka perlu adanya topologi dan konfigurasi jaringan yang tepat untuk mengoptimalkan koneksi antar terminal di Bandara Soekarno Hatta. Pada Penelitian ini, digunakan routing OSPF (Open Shortest Path First) dengan berbagai jenis topologi dan konfigurasi area untuk menentukan routing yang paling optimal yang dapat diterapkan di Bandara Soekarno Hatta.
\end{abstract}

Kata Kunci : Routing, OSPF, Bandara, Soekarno-Hatta

\section{PENDAHULUAN}

Bandar Udara Internasional Soekarno-Hatta (IATA:CGK) yang berada di Kecamatan Benda, Kota Tangerang, Provinsi Banten, merupakan bandara terbesar yang sekaligus menjadi bandara utama di Indonesia. Luas Bandara Soekarno-Hatta mencapai $18 \mathrm{~km}^{2}$, dengan rute penerbangan mencapai 1657 penerbangan setiap harinya, yang merupakan penerbangan terbanyak se-Indonesia Bandar Udara Internasional Soekarno-Hatta atau yang biasa disebut Bandara Soeta memiliki 3 Terminal, yaitu Terminal 1 atau T1, Terminal 2 atau T2 dan Terminal 3 atau T3. Terminal 1 terbagi menjadi sub-terminal A, B, dan C, Terminal 2 terbagi menjadi sub-terminal D, E, dan F, sedangkan Terminal 3 tetap dalam 1 bagian. Bandara Soeta dikelola oleh PT Angkasa Pura II (Persero). Oleh karena Bandara Soekarno Hatta yang begitu luas dan terdiri dari beberapa Terminal, maka penting untuk mengoptimalkan kinerja jaringan komputer sebagai media jalur komunikasi data di bandara tersebut.

Setiap protokol routing memiliki kelebihan dan kekurangan masing-masing. RIP dan OSPF salah satu dari dynamic routing. Namun OSPF lebih baik daripada RIP, karena RIP dapat menimbulkan routing loop dan menggunakan bandwith yang lebih besar.[5] Dapat dirumuskan masalah pada penelitian ini yaitu bagaimana menerapkan Protokol Routing OSPF pada jaringan di Bandara Soeta dengan menentukan model topologi dan area routing jaringan yang tepat. Tujuan dari penelitian ini adalah menerapkan model topologi dan konfigurasi Protokol Routing OSPF sehingga dapat menekan Konsumsi bandwidth dan mengoptimalkan dalam pengiriman data. 


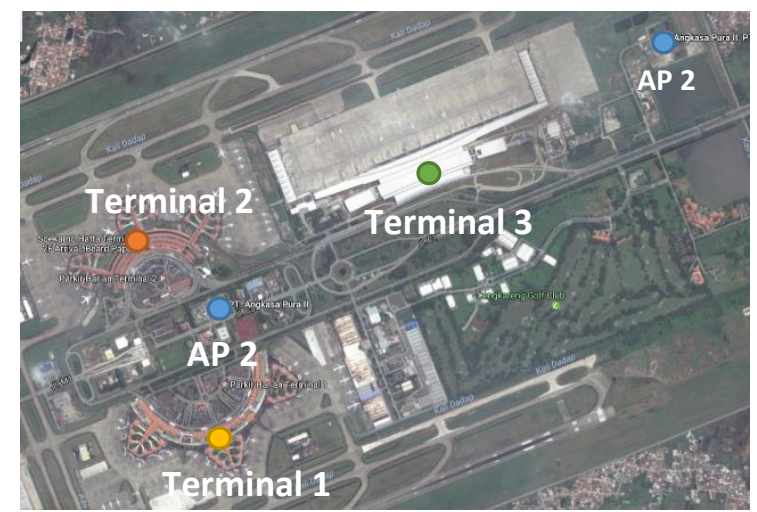

Gambar 1. Bandar Udara Internasional Soekarno-Hatta (CGK)

\section{METODE PENELITIAN}

Metode penelitian yang digunakan yaitu Observasi dan Pengumpulan Data, Analisis Kebutuhan Perancangan, Proses Implementasi dan Pengujian. Pada tahap observasi dan pengumpulan data, dilakukan pengumpulan materi dan pembelajaran mengenai prinsip kerja dynamic routing dan protokol routing OSPF. Kemudian pada tahap Analisis Kebutuhan Dan Perancangan, dilakukan proses analisis terhadap kebutuhan software dan hardware yang dibutuhkan serta perancangan sistem yang akan dibangun, berdasarkan hasil studi literatur yang ada. Dalam tahapan Proses Implementasi dan Pengujian dilakukan dari perancangan yang telah dibuat sebelumnya, mulai dari instalasi hingga pengujian sistem menggunakan traffic load untuk menentukan hasil optimalisasi sistem.

\section{HASIL PEMBAHASAN \\ Routing Open Shortest Path First (OSPF)}

Routing adalah proses menentukan rute dari host asal ke host tujuan [4]. Routing merupakan proses memindahkan data dari satu network ke network lain dengan cara meforward paket data via gateway. Routing menentukan kemana datagram akan dikirim agar mencapai tujuan yang diinginkan [1]. Informasi yang dibutuhkan router dalam melakukan routing yaitu:

1. Alamat Tujuan/Destination Address

2. Mengenal sumber informasi

3. Menemukan rute

4. Pemilihan rute

5. Menjaga informasi routing

OSPF bekerja berdasarkan algoritma Shortest Path First yang dikembangkan berdasarkan algoritma Dijkstra. Sebagai Interior Gateway protokol (IGP). Interior Gateway protokol atau Interior Routing Protokol dikembangkan untuk menghubungkan router-router dibawah kendali administrator jaringan.[1]

OSPF digunakan bersamaan dengan Internet protokol (IP), maksudnya paket OSPF dikirim bersamaan dengan header paket data IP. Setiap router OSPF mempunyai database yang identik yang menggambarkan topologi suatu Autonomous System yang disebut dengan Link State database (Topological database). Dari database ini, perhitungan Shortest Path First dilakukan untuk membentuk Routing Table. Perhitungan ulang terhadap Shortest Path First dilakukan apabila terjadi perubahan pada topologi jaringan. OSPF memungkinkan beberapa jaringan untuk dikelompokkan bersama. Pengelompokkan seperti ini dinamakan dengan area dan topologinya tersembunyi dari seluruh Autonomous System. Informasi yang tersembunyi ini memungkinkan penurunan traffic routing. Dengan menggunakan konsep area sistem penyebaran informasinya menjadi lebih teratur dan tersegmentasi. Dengan adanya distribusi 
routing yang teratur, maka penggunaan bandwidth akan lebih efisien, lebih cepat mencapai konvergensi, dan lebih presisi dalam menentukan rute terbaik dalam mengirim paket.[5]

Pada penelitian ini diterapkan alur desain dan uji coba sistem sebagai berikut:

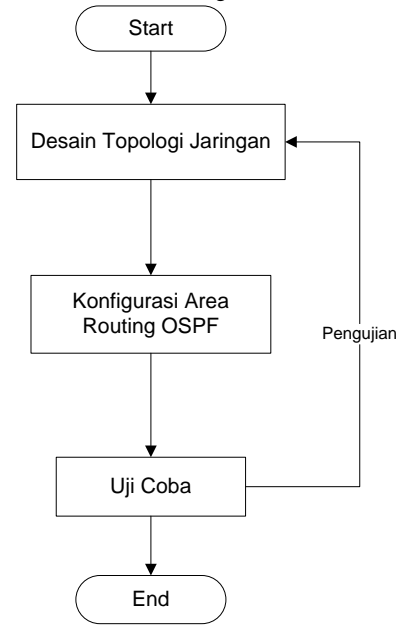

Gambar 2. Alur Desain Implementasi dan Uji Coba Sistem

\section{Konfigurasi Pc Client}

Untuk masing- masing Router ditambahkan PC (Personal Computer) sebagai client dan disetting pada IP Configuration.

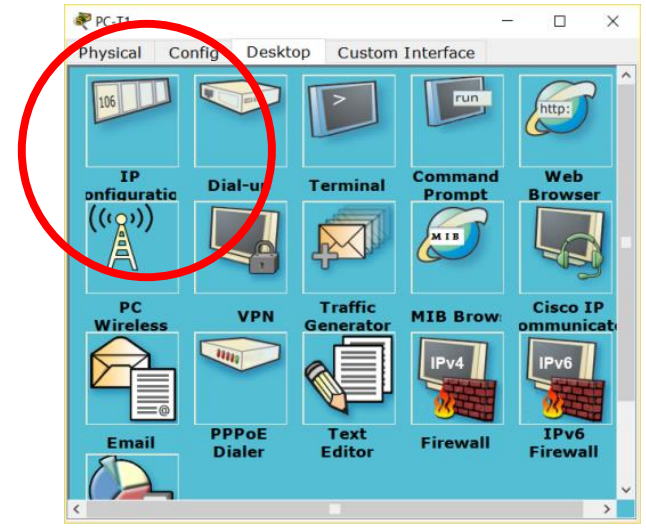

Gambar 3. Properties PC

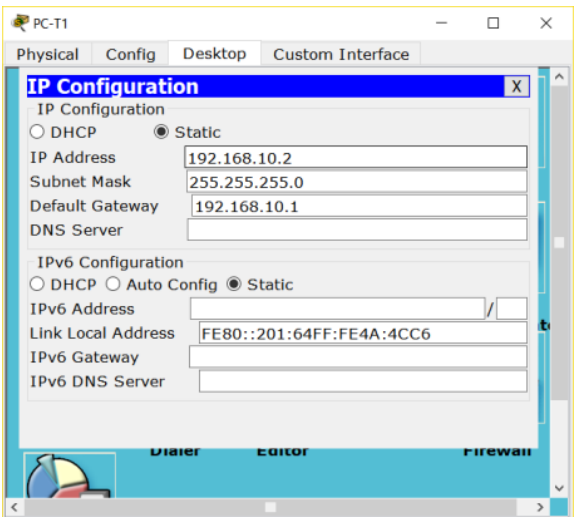

Gambar 4. Menu Tab IP Configuration PC 
Dalam penelitian ini, IP PC di masing-masing Router akan disetting sebagai berikut:

Berikut nama PC simulasi, IP Address PC dan koneksi router. Gateway adalah IP address Router yang terhubung langsung ke PC Client.

Tabel 1. Nama PC dan Router

\begin{tabular}{|c|c|l|}
\hline LOKASI & $\begin{array}{c}\text { PERSONAL } \\
\text { COMPUTER }\end{array}$ & ROUTER \\
\hline $\begin{array}{c}\text { Terminal } \\
1\end{array}$ & PC-T1 & R-T1 \\
\hline $\begin{array}{c}\text { Kantor } \\
\text { AP 2 }\end{array}$ & PC-AP2 & R-AP2 \\
\hline $\begin{array}{c}\text { Terminal } \\
2\end{array}$ & PC-T2 & R-T2 \\
\hline $\begin{array}{c}\text { Terminal } \\
3\end{array}$ & PC-T3 & R-T3 \\
\hline $\begin{array}{c}\text { Kantor } \\
\text { AP 2 }\end{array}$ & PC-AP2_2 & R-AP2_2 \\
\hline
\end{tabular}

Tabel 2. IP Anddress dan Gateway PC

\begin{tabular}{|l|l|l|}
\hline $\begin{array}{l}\text { PERSONAL } \\
\text { COMPUTER }\end{array}$ & $\begin{array}{l}\text { IP } \\
\text { ADDRESS }\end{array}$ & GATEWAY \\
\hline PC-T1 & 192.168 .10 .2 & 192.168 .10 .1 \\
\hline PC-AP2 & 192.168 .20 .2 & 192.168 .20 .1 \\
\hline PC-T2 & 192.168 .30 .2 & 192.168 .30 .1 \\
\hline PC-T3 & 192.168 .40 .2 & 192.168 .40 .1 \\
\hline PC-AP2_2 & 192.168 .50 .2 & 192.168 .50 .1 \\
\hline
\end{tabular}

Berikut nama router simulasi dan lokasinya, beserta IP Addressnya.

\begin{tabular}{|l|l|l|}
\hline $\begin{array}{l}\text { NAMA } \\
\text { ROUTER }\end{array}$ & $\begin{array}{l}\text { IP Address } \\
\text { Port } \\
\text { FastEthernet } \\
\text { 0/0 } \\
\text { Connect to } \\
\text { PC }\end{array}$ & $\begin{array}{l}\text { IP Address } \\
\text { Port } \\
\text { FastEthernet } \\
\text { 1/0 } \\
\text { Connect to } \\
\text { Backbone }\end{array}$ \\
\hline R-T1 & 192.168 .10 .1 & 192.168 .1 .1 \\
\hline R-AP2 & 192.168 .20 .1 & 192.168 .1 .2 \\
\hline R-T2 & 192.168 .30 .1 & 192.168 .1 .3 \\
\hline R-T3 & 192.168 .40 .1 & 192.168 .1 .4 \\
\hline R-AP2_2 & 192.168 .50 .1 & 192.168 .1 .5 \\
\hline
\end{tabular}


Berikut konfigurasi IP Address router pada interfacenya. pada Router

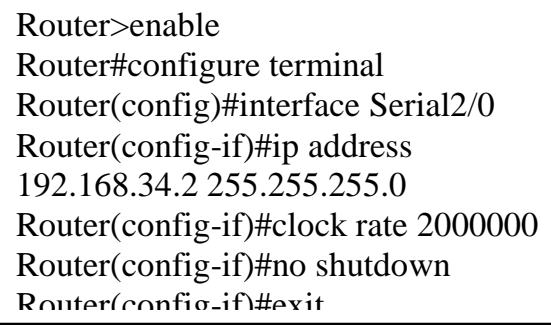

\section{Jaringan Single Area Pada Topologi Star}

Berikut model topologi jaringan single area dengan routing OSPF, dan konfigurasi jaringannya.. Desain topologi terdiri dari 1 area yaitu Area 0 .

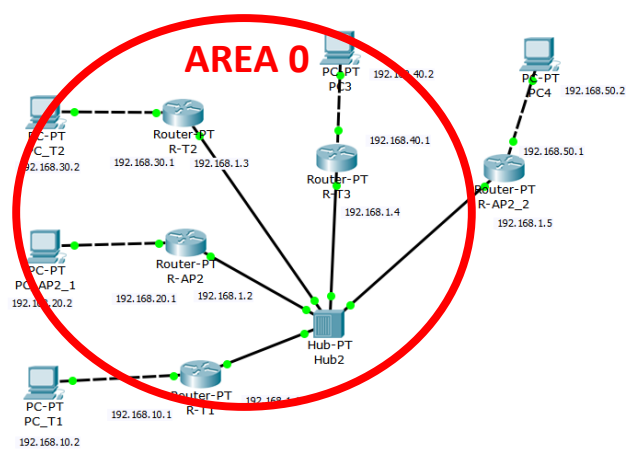

Gambar 5. Model 1 Area Topologi Star

Tabel 3. Konfigurasi Routing OSPF Single Area dengan Topologi Star

\begin{tabular}{|l|}
\hline R-T1 \\
\hline Router>en \\
Router\#config terminal \\
Router(config)\#router ospf 1 \\
Router(config-router)\#network \\
192.168.10.0 0.0.0.255 area 0 \\
Router(config-router)\#network \\
192.168.1.0 0.0.0.255 area 0 \\
Router(config-router)\#^Z \\
Router\#wr \\
Building configuration... \\
[OK] \\
\hline R-AP2 \\
\hline Router(config)\#router ospf 1 \\
Router(config-router)\#network \\
192.168.20.0 0.0.0.255 area 0 \\
Router(config-router)\#network \\
192.168.1.0 0.0.0.255 area 0 \\
\hline R-T2 \\
\hline Router(config)\#router ospf 1 \\
Router(config-router)\#network \\
192.168.30.0 0.0.0.255 area 0 \\
Router(config-router)\#network \\
192.168.1.0 0.0.0.255 area 0 \\
\hline
\end{tabular}




\begin{tabular}{|l|}
\hline R-T3 \\
\hline Router(config)\#router ospf 1 \\
Router(config-router)\#network \\
192.168.40.0 0.0.0.255 area 0 \\
Router(config-router)\#network \\
192.168.1.0 0.0.0.255 area 0 \\
\hline R-AP2_2 \\
\hline Router(config)\#router ospf 1 \\
Router(config-router)\#network \\
192.168.50.0 0.0.0.255 area 0 \\
Router(config-router)\#network \\
192.168.1.0 0.0.0.255 area 0 \\
\hline
\end{tabular}

\section{Jaringan Single Area Pada Topologi Ring}

Berikut model topologi dan konfigurasi Routing OSPF Single Area dengan Topologi Ring:

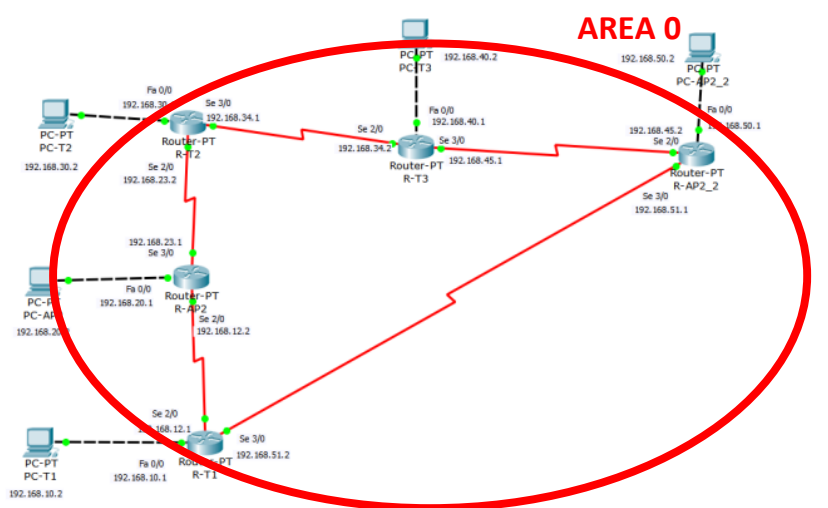

Gambar 6. Model 1 Area Topologi Ring

Tabel 4. Konfigurasi Routing OSPF Single Area dengan Topologi Ring

\begin{tabular}{|l|}
\hline R-T1 \\
\hline Router>en \\
Router\#config terminal \\
Router(config)\#router ospf 1 \\
Router(config-router)\#network \\
192.168.10.0 0.0.0.255 area 0 \\
Router(config-router)\#network \\
192.168.12.0 0.0.0.255 area 0 \\
Router(config-router)\#network \\
192.168.51.0 0.0.0.255 area 0 \\
Router(config-router)\#^Z \\
Router\#wr \\
Building configuration... \\
[OK] \\
\hline R-AP2 \\
\hline Router(config)\#router ospf 1 \\
Router(config-router)\#network \\
192.168.20.0 0.0.0.255 area 0 \\
Router(config-router)\#network \\
\hline
\end{tabular}




\begin{tabular}{|l|}
\hline 192.168.23.0 0.0.0.255 area 0 \\
Router(config-router)\#network \\
192.168 .12 .0 0.0.0.255 area 0 \\
\hline R-T2 \\
\hline Router(config)\#router ospf 1 \\
Router(config-router)\#network \\
192.168.30.0 0.0.0.255 area 0 \\
Router(config-router)\#network \\
192.168.23.0 0.0.0.255 area 0 \\
Router(config-router)\#network \\
192.168.34.0 0.0.0.255 area 0 \\
\hline R-T3 \\
\hline Router(config)\#router ospf 1 \\
Router(config-router)\#network \\
192.168.40.0 0.0.0.255 area 0 \\
Router(config-router)\#network \\
192.168.34.0 0.0.0.255 area 0 \\
Router(config-router)\#network \\
192.168.45.0 0.0.0.255 area 0 \\
\hline R-AP2_2 \\
\hline Router(config)\#router ospf 1 \\
Router(config-router)\#network \\
192.168.50.0 0.0.0.255 area 0 \\
Router(config-router)\#network \\
192.168.45.0 0.0.0.255 area 0 \\
Router(config-router)\#network \\
192.168.51.0 0.0.0.255 area 0 \\
\hline
\end{tabular}

\section{Jaringan 2 Area Pada Topologi Ring}

Berikut model topologi dan konfigurasi Routing OSPF 2 Area dengan Topologi Ring:

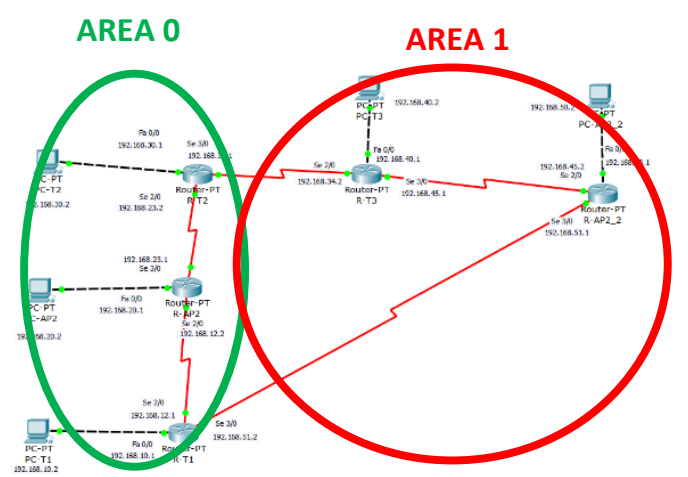

Gambar 7. Model 2 Area Topologi Ring 
Tabel 5. Konfigurasi Routing OSPF 2 Area dengan Topologi Ring

\begin{tabular}{|l|}
\hline R-T1 \\
\hline Router>en \\
Router\#config terminal \\
Router(config)\#router ospf 1 \\
Router(config-router)\#network \\
192.168.10.0 0.0.0.255 area 0 \\
Router(config-router)\#network \\
192.168.12.0 0.0.0.255 area 0 \\
Router(config-router)\#network \\
192.168.51.0 0.0.0.255 area 1 \\
Router(config-router)\#^Z \\
Router\#wr \\
Building configuration... \\
[OK] \\
\hline R-AP2 \\
\hline Router(config)\#router ospf 1 \\
Router(config-router)\#network \\
192.168.20.0 0.0.0.255 area 0 \\
Router(config-router)\#network \\
192.168.23.0 0.0.0.255 area 0 \\
Router(config-router)\#network \\
192.168.12.0 0.0.0.255 area 0 \\
\hline R-T2 \\
\hline Router(config)\#router ospf 1 \\
Router(config-router)\#network \\
192.168.30.0 0.0.0.255 area 0 \\
Router(config-router)\#network \\
192.168.23.0 0.0.0.255 area 0 \\
Router(config-router)\#network \\
192.168.34.0 0.0.0.255 area 1 \\
\hline R-T3 \\
\hline Router(config)\#router ospf 1 \\
Router(config-router)\#network \\
192.168.40.0 0.0.0.255 area 1 \\
Router(config-router)\#network \\
192.168.34.0 0.0.0.255 area 1 \\
Router(config-router)\#network \\
192.168.45.0 0.0.0.255 area 1 \\
\hline R-AP2_2 \\
\hline Router(config)\#router ospf 1 \\
Router(config-router)\#network \\
Router(config-router)\#network \\
\hline
\end{tabular}


Jaringan 3 Area Pada Topologi Ring

Berikut model topologi dan konfigurasi Routing OSPF 3 Area dengan Topologi Ring:

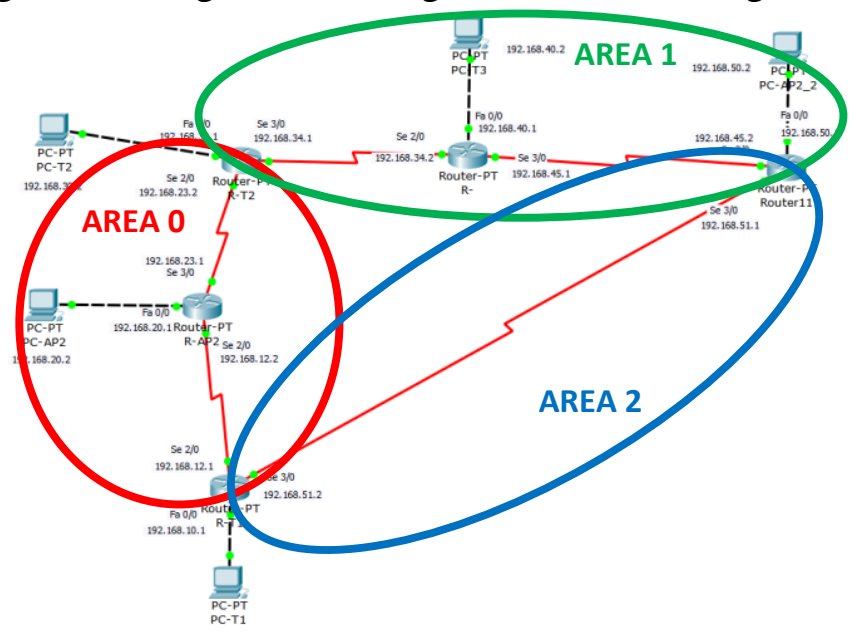

Gambar 8. Model 3 Area Topologi Ring

Tabel 6. Konfigurasi Routing OSPF Single Area dengan Topologi Ring

\begin{tabular}{|l|}
\hline R-T1 \\
\hline Router>en \\
Router\#config terminal \\
Router(config)\#router ospf 1 \\
Router(config-router)\#network \\
192.168.10.0 0.0.0.255 area 2 \\
Router(config-router)\#network \\
192.168.12.0 0.0.0.255 area 0 \\
Router(config-router)\#network \\
192.168.51.0 0.0.0.255 area 2 \\
Router(config-router)\#^Z \\
Router\#wr \\
Building configuration... \\
[OK] \\
\hline R-AP2 \\
\hline Router(config)\#router ospf 1 \\
Router(config-router)\#network \\
192.168.20.0 0.0.0.255 area 0 \\
Router(config-router)\#network \\
192.168.23.0 0.0.0.255 area 0 \\
Router(config-router)\#network \\
192.168.12.0 0.0.0.255 area 0 \\
\hline R-T2 \\
\hline Router(config)\#router ospf 1 \\
Router(config-router)\#network \\
192.168.30.0 0.0.0.255 area 0 \\
Router(config-router)\#network \\
192.168.23.0 0.0.0.255 area 0 \\
Router(config-router)\#network \\
192.168.34.0 0.0.0.255 area 1 \\
\end{tabular}




\begin{tabular}{|l|}
\hline R-T3 \\
\hline Router(config)\#router ospf 1 \\
Router(config-router)\#network \\
192.168.40.0 0.0.0.255 area 1 \\
Router(config-router)\#network \\
192.168.34.0 0.0.0.255 area 1 \\
Router(config-router)\#network \\
192.168.45.0 0.0.0.255 area 1 \\
\\
\hline R-AP2_2 \\
\hline Router(config)\#router ospf 1 \\
Router(config-router)\#network \\
192.168.50.0 0.0.0.255 area 1 \\
Router(config-router)\#network \\
192.168.45.0 0.0.0.255 area 1 \\
Router(config-router)\#network \\
192.168.51.0 0.0.0.255 area 2 \\
\end{tabular}

Untuk melihat jalur routing, dapat tampilkan dengan perintah "show ip route" pada masingmasing router. Berikut salah satu IP route pada Router1:

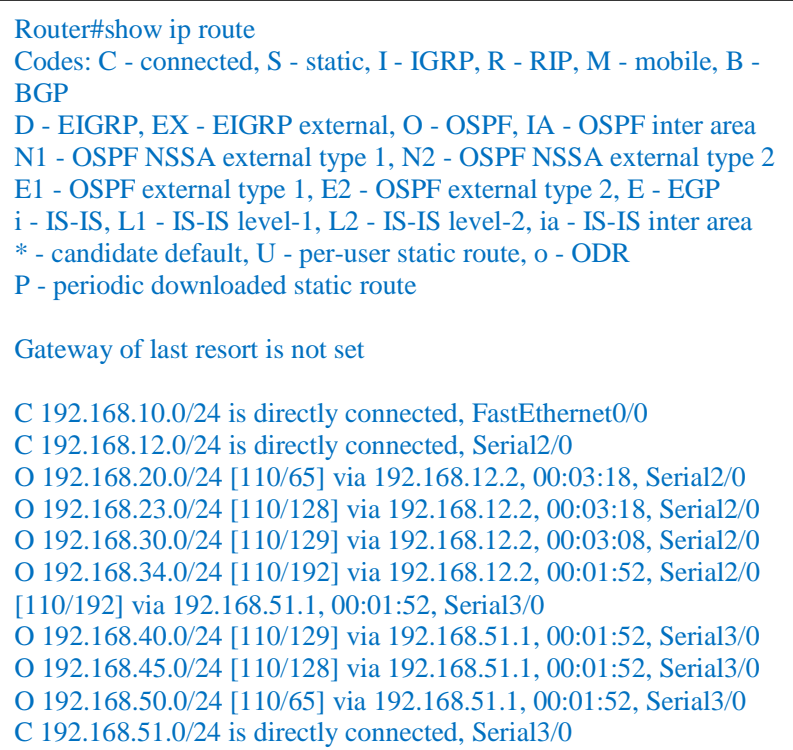

Untuk melihat IP tetangga pada routing OSPF yang telah di konfigurasikan, dapat tampilkan dengan perintah "show ip ospf neighbor" pada masing-masing router. Berikut salah satu IP neighbor pada Router1:

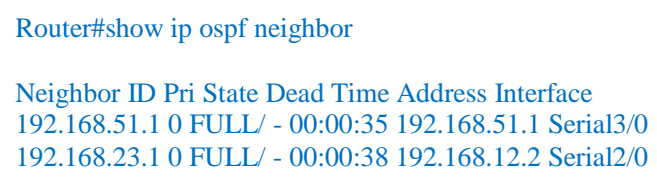


Untuk melihat basis data routing OSPF yang telah di konfigurasikan pada suatu router, dapat tampilkan dengan perintah "show ip ospf database". Berikut salah satu basisdata IP pada Router1:

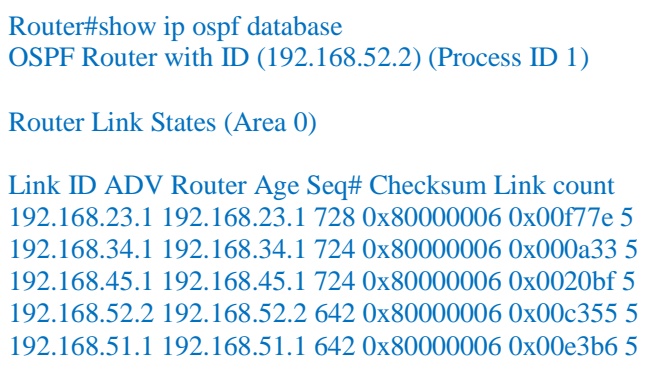

\section{Simulasi Pengujian}

1. Pengujian dilakukan dengan simulasi pengiriman paket, menggunakan Traffic Generator di masing-masing PC. Setting ini berlaku untuk setiap PC pada semua Model area yang akan diujikan. Pada traffic generator diisikan variable berikut: TTL (Time to Live) yaitu 255, nilai TOS (Time of Service) yaitu 255, Sequence Number $=1$ dan size untuk beban 14000 bit. TTL merupakan lama waktu paket saat mengirim hingga sampai lagi.

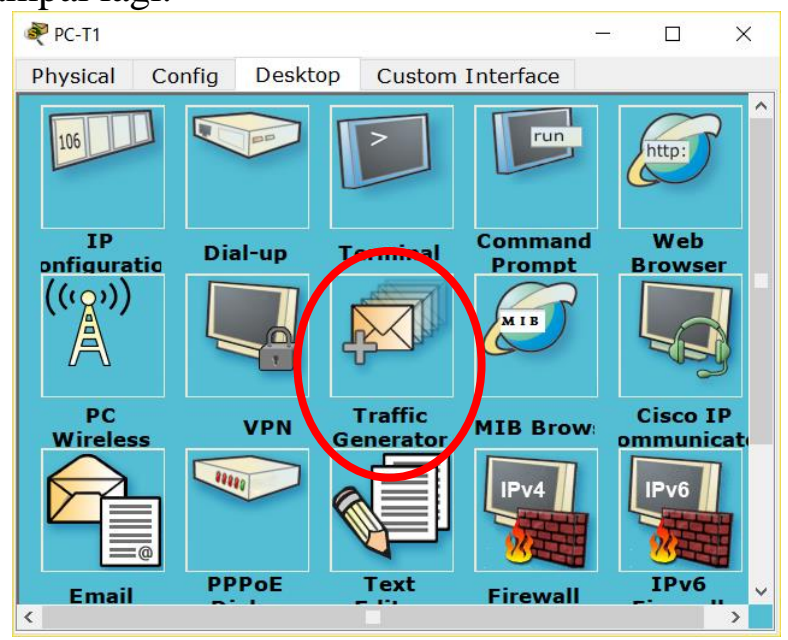

Gambar 9. Properties PC 


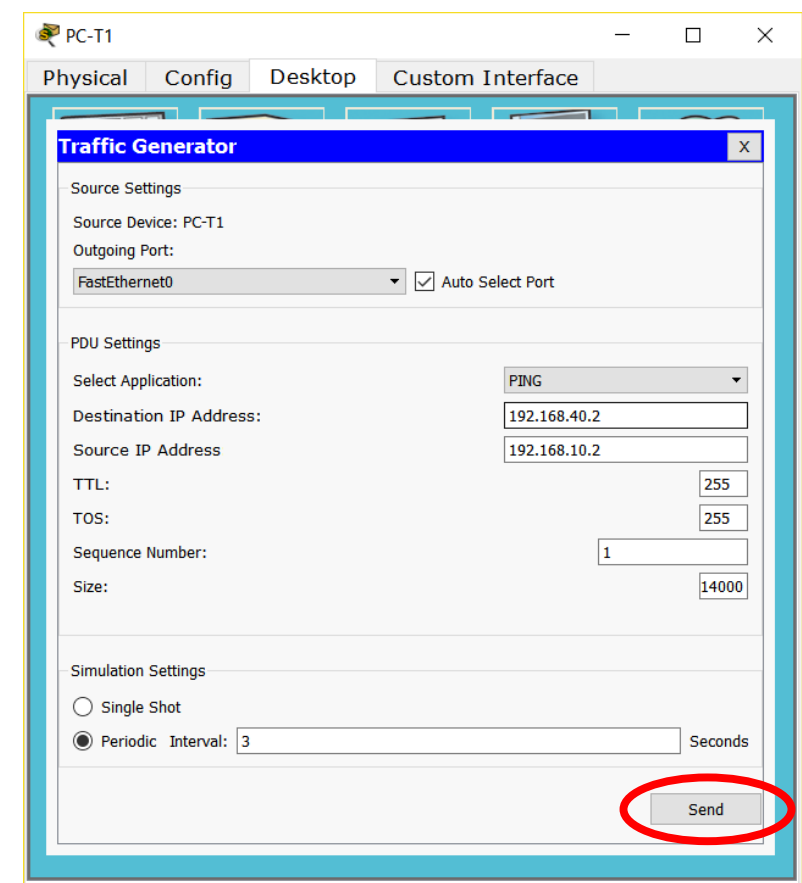

Gambar 10. Menu Tab Traffic Generator

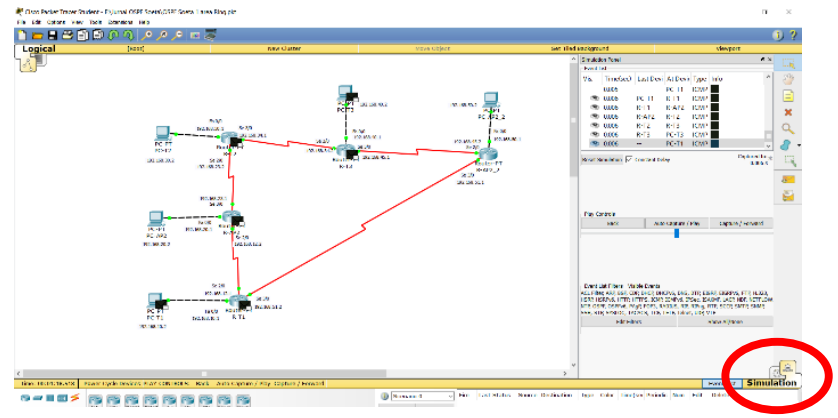

Source IP Address : PC T1 - 192.168.10.2

Destination IP Address : PC T3 - 192.168.40.2

\begin{tabular}{|l|l|l|l|l|l|l|}
\hline Source IP & Destination & \multicolumn{4}{|l|}{ TIME (SECOND) MODEL OSPF } \\
\cline { 4 - 7 } Address & IP Address & $\begin{array}{l}\text { Area } \\
\text { Topologi } \\
\text { Star }\end{array}$ & $\begin{array}{l}\text { Area } \\
\text { Topologi } \\
\text { Ring }\end{array}$ & $\begin{array}{l}\text { Area } \\
\text { Topologi } \\
\text { Ring }\end{array}$ & $\begin{array}{l}\text { Area } \\
\text { Topologi } \\
\text { Ring }\end{array}$ \\
\hline 192.168 .10 .2 & 192.168 .40 .2 & 0.10 & 0.010 & 0.008 & 0.010 \\
\hline
\end{tabular}

Berikut perjalanan paket, routing dari device PC pada Terminal 1 menuju device PC pada Terminal 3, hingga kembali lagi ke device awal.

Source IP Address : PC T1 - 192.168.10.2

Destination IP Address : PC T3 - 192.168.40.2

\begin{tabular}{|c|c|c|c|}
\hline \multicolumn{4}{|c|}{ ROUTING PENGIRIMAN PAKET } \\
\hline $\begin{array}{l}1 \text { Area } \\
\text { Topologi } \\
\text { Star }\end{array}$ & $\begin{array}{l}1 \quad \text { Area } \\
\text { Topologi } \\
\text { Ring }\end{array}$ & $\begin{array}{l}2 \text { Area } \\
\text { Topologi } \\
\text { Ring }\end{array}$ & $\begin{array}{l}3 \quad \text { Area } \\
\text { Topologi } \\
\text { Ring }\end{array}$ \\
\hline
\end{tabular}




\begin{tabular}{|c|c|c|c|}
\hline $\begin{array}{l}\text { 1. } \mathrm{PC}-\mathrm{T} 1 \\
\text { 2. } \mathrm{R}-\mathrm{T} 1 \\
\text { 3. } \mathrm{R}- \\
\mathrm{AP} 2 \\
\text { 4. } \mathrm{R}-\mathrm{T} 2 \\
\text { 5. } \mathrm{R}-\mathrm{T} 3 \\
\text { 6. } \mathrm{PC}-\mathrm{T} 3 \\
\text { 7. } \mathrm{R}-\mathrm{T} 3 \\
\text { 8. R - T2 } \\
\text { 9. R - } \\
\mathrm{AP} 2 \\
\text { 10. R-T1 } \\
\text { 11. PC - } \\
\mathrm{T} 1\end{array}$ & $\begin{array}{l}\text { 1. } \mathrm{PC}- \\
\mathrm{T} 1 \\
\text { 2. } \mathrm{R}-\mathrm{T} 1 \\
\text { 3. } \mathrm{R}- \\
\mathrm{AP} 2 \\
\text { 4. } \mathrm{R}-\mathrm{T} 2 \\
\text { 5. } \mathrm{R}-\mathrm{T} 3 \\
6 . \quad \mathrm{PC} \quad- \\
\mathrm{T} 3 \\
\text { 7. } \mathrm{R}-\mathrm{T} 3 \\
8 . \mathrm{R}-\mathrm{T} 2 \\
9 . \quad \mathrm{R}- \\
\mathrm{AP} 2 \\
10 . \quad \mathrm{R}- \\
\mathrm{T} 1 \\
11 . \quad \mathrm{PC}- \\
\mathrm{T} 1\end{array}$ & $\begin{array}{l}\text { 1. } \mathrm{PC}- \\
\mathrm{T} 1 \\
\text { 2. } \mathrm{R}-\mathrm{T} 1 \\
\text { 3. } \mathrm{R}- \\
\mathrm{AP} 2 \\
\text { 4. } \mathrm{R}-\mathrm{T} 3 \\
\text { 6. } \mathrm{PC}- \\
\mathrm{T} 3 \\
\text { 7. } \mathrm{R}-\mathrm{T} 3 \\
\text { 8. } \mathrm{R}-\mathrm{T} 1 \\
\text { 9. PC - } \\
\mathrm{T} 1\end{array}$ & $\begin{array}{l}\text { 1. } \mathrm{PC}- \\
\mathrm{T} 1 \\
\text { 2. } \mathrm{R}-\mathrm{T} 1 \\
\text { 3. } \mathrm{R}- \\
\mathrm{AP} 2 \\
\text { 4. } \mathrm{R}-\mathrm{T} 2 \\
\text { 5. } \mathrm{R}-\mathrm{T} 3 \\
6 . \quad \mathrm{PC}- \\
\mathrm{T} 3 \\
\text { 7. } \mathrm{R}-\mathrm{T} 3 \\
\text { 8. } \mathrm{R}-\mathrm{T} 2 \\
\text { 9. } \mathrm{R}- \\
\mathrm{AP} 2 \\
\text { 10. } \mathrm{R}- \\
\mathrm{T} 1 \\
11 . \mathrm{PC}- \\
\mathrm{T} 1\end{array}$ \\
\hline
\end{tabular}

Disikan Nilai TTL (Time to Live) yaitu 255, nilai TOS (Time of Service) yaitu 255, source port 80, destination port 21 dan size 10000 bit. Setting ini berlaku untuk setiap PC pada semua Model area yang akan diujikan.

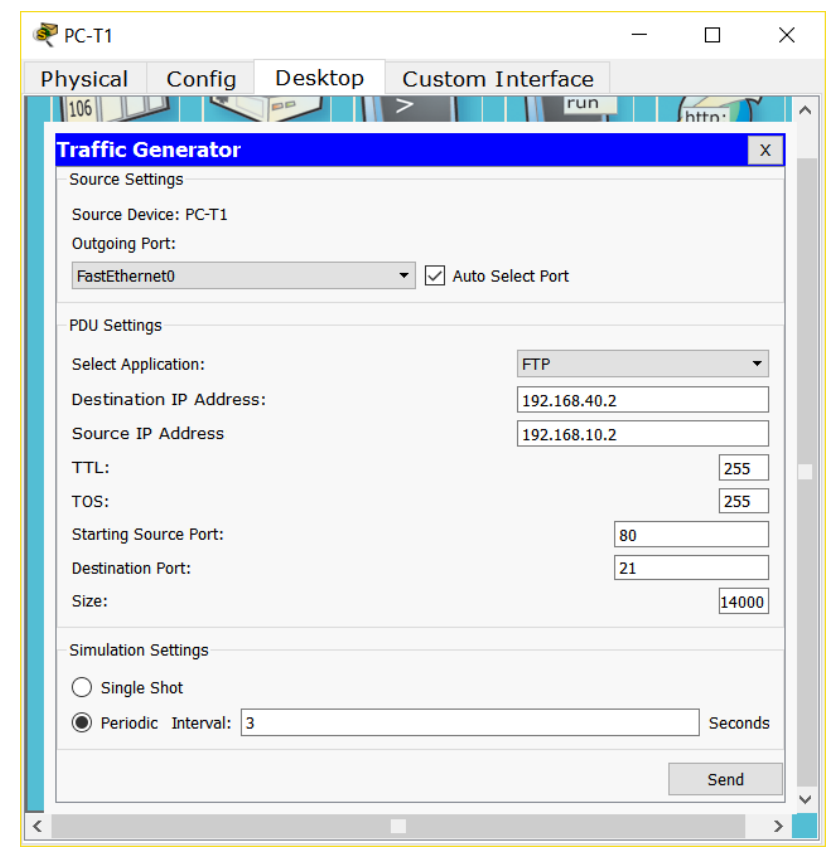

\begin{tabular}{|c|c|c|c|}
\hline \multicolumn{4}{|c|}{ ROUTING PENGIRIMAN PAKET } \\
\hline $\begin{array}{l}1 \quad \text { Area } \\
\text { Topologi } \\
\text { Star }\end{array}$ & $\begin{array}{l}\text { Area } \\
\text { Topologi } \\
\text { Ring }\end{array}$ & $\begin{array}{l}2 \text { Area } \\
\text { Topologi } \\
\text { Ring }\end{array}$ & $\begin{array}{l}3 \quad \text { Area } \\
\text { Topologi } \\
\text { Ring }\end{array}$ \\
\hline $\begin{array}{l}\text { 1. } \mathrm{PC}-\mathrm{T} 1 \\
\text { 2. } \mathrm{R}-\mathrm{T} 1 \\
\text { 3. } \mathrm{R}- \\
\mathrm{AP} 2\end{array}$ & $\begin{array}{l}\text { 1. } \mathrm{PC}- \\
\mathrm{T} 1 \\
\text { 2. } \mathrm{R}-\mathrm{T} 1 \\
\text { 3. } \mathrm{R}-\end{array}$ & $\begin{array}{l}\text { 1. } \mathrm{PC}- \\
\mathrm{T} 1 \\
\text { 2. } \mathrm{R}-\mathrm{T} 1 \\
\text { 3. } \mathrm{R}-\end{array}$ & $\begin{array}{l}\text { 1. } \mathrm{PC}- \\
\mathrm{T} 1 \\
\text { 2. } \mathrm{R}-\mathrm{T} 1 \\
\text { 3. } \mathrm{R}-\end{array}$ \\
\hline
\end{tabular}




\begin{tabular}{|c|c|c|c|}
\hline $\begin{array}{l}\text { 4. } \mathrm{R}-\mathrm{T} 2 \\
\text { 5. } \mathrm{R}-\mathrm{T} 3 \\
\text { 6. } \mathrm{PC}-\mathrm{T} 3 \\
\text { 7. } \mathrm{R}-\mathrm{T} 3 \\
\text { 8. } \mathrm{R}-\mathrm{T} 2 \\
\text { 9. } \mathrm{R}- \\
\mathrm{AP} 2 \\
\text { 10. } \mathrm{R}-\mathrm{T} 1 \\
\text { 11. PC - } \\
\mathrm{T} 1\end{array}$ & $\begin{array}{l}\mathrm{AP} 2 \\
4 . \mathrm{R}-\mathrm{T} 2 \\
5 . \mathrm{R}-\mathrm{T} 3 \\
6 . \mathrm{PC}- \\
\mathrm{T} 3 \\
7 . \mathrm{R}-\mathrm{T} 3 \\
8 . \mathrm{R}-\mathrm{T} 2 \\
9 . \quad \mathrm{R}- \\
\mathrm{AP} 2 \\
10 . \mathrm{R}- \\
\mathrm{T} 1 \\
11 . \mathrm{PC}- \\
\mathrm{T} 1\end{array}$ & $\begin{array}{l}\mathrm{AP} 2 \\
\text { 4. } \mathrm{R}-\mathrm{T} 3 \\
6 . \mathrm{PC}- \\
\mathrm{T} 3 \\
\text { 7. } \mathrm{R}-\mathrm{T} 3 \\
\text { 8. } \mathrm{R}-\mathrm{T} 1 \\
\text { 9. PC - } \\
\mathrm{T} 1\end{array}$ & $\begin{array}{l}\mathrm{AP} 2 \\
\text { 4. } \mathrm{R}-\mathrm{T} 2 \\
5 . \mathrm{R}-\mathrm{T} 3 \\
6 . \mathrm{PC}- \\
\mathrm{T} 3 \\
\text { 7. } \mathrm{R}-\mathrm{T} 3 \\
8 . \mathrm{R}-\mathrm{T} 2 \\
9 . \mathrm{R}- \\
\mathrm{AP2} \\
10 . \mathrm{R}- \\
\mathrm{T} 1 \\
11 . \mathrm{PC}- \\
\mathrm{T} 1\end{array}$ \\
\hline
\end{tabular}

\section{KESIMPULAN}

Dari pengujian diatas, penurunan rata-rata time antara area pada Traffic Load untuk Application Ping secara garis besar 0,067\%, dan penurunan rata-rata time untuk Application FTP secara garis besar $0,15 \%$. Semakin kecilnya nilai time menunjukkan bahwa pengiriman paket semakin cepat, hal ini menunjukkan bahwa kinerja routing semakin optimal. Maka dapat disimpulkan bahwa semakin banyak area pada jaringan OSPF dan pengelompokan area yang tepat, maka semakin optimal model routing OSPF. Dengan semakin optimal kinerja routing, maka dapat menekan kinerja Processor, Kebutuhan memori dan Konsumsi bandwidth. Oleh karena itu yang terpenting pada jaringan OSPF adalah perancangan topologi jaringan dan konfigurasi routing OSPF yang tepat. Perancangan topologi jaringan yang baik dapat mempengaruhi kinerja sistem secara keseluruhan.

\section{DAFTAR PUSTAKA}

Lin, Ying-Dar., Hwang Ren-Hun., Baker, F. 2012. Computer Network An Open Source Approuch, McGraw - Hill International Edition.

MikroTik. 2007. MikroTik RouterOS ${ }^{\mathrm{TM}}$ v2.9 Reference Manual. Mikrotikls SIA.

Parziale, L., Britt, D., Davis, C., Forrester, J., Liu, W., Matthews, C., Rosselot, N. 2006. TCP/IP Tutorial and Technical Overview, Redbooks IBM,.

Sofana, Iwan. 2008. Membangun Jaringan Komputer, Membuat jaringan Komputer (Wire \& Wireless) Untuk Pengguna Windows dan Linux. Bandung. Informatika.

Syafrizal, Melwin. 2005. Pengantar Jaringan Komputer. Yogyakarta. ANDI Yogyakarta. 